in which the metals were specific fruits of the earth. In spite of his chemical pathology Paracelsus tends toward localizing disease on his firmament of organs. But disease is essentially the result of an extraneous force, an invader, a seed. This specific agent has to be treated etiologically by specific remedies (ancient therapy was non-specific), which are often chemicals. Paracelsus paid particular attention to diseases due to tartar, fought the doctrine of catarrh, and developed a new theory of plague. He began to replace medieval uroscopy by quantitative and chemical analysis of urine. The author gives a long list of his practical achievements in medicine, always com bined with wild speculations (antiseptic principles, syphilis, mercury as a diuretic, hydrotelluric theory of goitre, balneology, miners' diseases).

Dr. Pagel then analyses with wonderful seholarship and great penetration the sources of Paracelsus: gnosticism, the Cabbala, neoplatonism, Avicebron, Ramon, Lull, Arnuld of Villanova, the alchemists John de Rupeseissa, Reuchlin, and Agrippa of Nettesheym. He also discusses in detail Paracelsus's great critic, Erastus, and his moderate defender, Daniel Sennert.

Paracelsus was, according to the author, an able chemist, and his medicine has elements of what was to become modern medicine. But his chemistry and his medicine were but parts of his symbolistic, decidedly unscientific cosmology and philosophy. He produced scientific results from a non-scientific world of motives and thoughts. He offered little which in principle cannot be found with his medieval predecessors, but he integrated all these elements into a new doctrine of medicine and natural philosophy. Without Paracelsus there would have been no iatrochemistry. $\mathrm{He}$ was a 'Magus' who forged a new synthesis from personal experience.

I do not hesitate to rate this book as the most valuable in the whole extensive literature on Paracelsus from the point of documentation as well as judgment. It is a high point in the author's long and distinguished career as a medical historian, which began with his work on van Helmont in the late 1920 's and continued the great accomplishments of his father, Julius Pagel. It avoids equally the nebulous enthusiasm and the embittered hostility encountered so often in writings on Paracelsus. Dr. Pagel unites an unqualified attachment to modern science with a profound feeling for and understanding of mystic and magic philosophy. This rare combination ensbles him to be just and to give us the quintessence of Paracelsus. ERwin H. ACkerknecht

\section{MEDICINE IN INDUSTRY}

Industrial Hygiene and Toxicology

Edited by Frank A. Patty. Vol. 1: General Principles. Second, revised edition. Pp. xxvii +830 . (New York : Interscience Publishers, Inc.; London: Interscience Publishers, Ltd., 1958.) 17.50 dollars.

TTHE first edition of Patty's "Industrial Hygiene 1 and Toxicology" was published in 1948 in two volumes. The second edition is to be in three volumes, of which the first is now ready. It is not possible to assess the whole work until it finally appears, but, according to the preface to the second edition, much of the new matter has been placed in the first volume. The main changes are to be found in the treatment of such subjects as noise, heat, ionizing radiations, human engineering and industrial safety, sanitation, air pollution and illumination. Additional chapters on air conditioning, air cleaning, and heat control in the hot industries are included, as well as separate chapters on illumination and industrial sanitation. Dr. O. A. Sander contributes a revised chapter on the pulmonary dust diseases, Dr. L. Schwartz and Dr. Carey McCord bring up to date their chapters on the industrial dermatoses and the visible marks of occupation, respectively. The editor, Mr. Frank Patty, is responsible for four chapters on such subjects as the industrial hygiene survey, the mode of entry and action of toxic materials and sampling and analysis of atmospheric contaminants, in addition to his introductory chapter on industrial hygiene. This chapter calls for some comment, because Mr. Patty seems to have the idea that analyses of the contaminants of factory atmospheres did not begin in Great Britain until the formation of the Occupational Hygiene Society in April 1953, and that until that date medical control and not engineering control of health risks had been used. The fact is that both methods of control have been used in Great Britain for many years. Nevertheless, industrial or occupational hygiene is a rapidly developing subject, and the industrial health engineer is a new importation from the United States.

The first edition of Mr. Patty's book was an ambitious, but rather uneven, attempt to bring all the facets of industrial hygiene within the same close and curtilage. It showed that the industrial health engineer has the freedom of engineering, chemistry, physics, biology, physiology and medicine, and speaks with equal authority on all of them. In this age of super-specialization, the health engineer is therefore a refreshing phenomenon. The engineer who writes with authority on clinical medicine and hæmatology, without the benefit of a medical training, is to be congratulated on his courage. No doctor with experience of industry has yet been bold enough to write and edit a book on engineering. But that state of affairs may yet arise, because the industrial doctor in Britain is obliged to make himself familiar with the intimate details of factory processes, and with the estimations of contaminants in the atmosphere and its engineering control. In the United States it is rare for the plant doctor to deal with such matters, which are left to the health engineer, or industrial hygienist. It seems to us in Britain that the American version of the health engineer is probably taking on too much responsibility for health matters. No doubt in the course of time the industrial hygienist will find his proper place. Mr. Patty himself shows that the position in the States is being slowly modified. "Industrial hygiene," he writes, "has successfully withstood abortive efforts at absorption by both safety engineering and medicine. It borders on each of those fields, but differs in technique from both, and one of its primary functions is to get these two groups to work hand in hand." He has little doubt that regular and more frequent medical examinations are a desirable way of discovering dangerous exposures, especially in the absence of competent industrial hygiene engineering and control; and he affirms that when the two methods are properly co-ordinated, the most dependable safeguard against harmful exposures is provided. He has yet to reach the logical conclusion that the major responsibility for health matters in industry rests with the medical profession, assisted, as it should be, by capable and knowledgeable industrial hygienists.

A. I. G. McLaughuin 